\title{
Analysis of the Release Process of Phenylpropanolamine Hydrochloride from Ethylcellulose Matrix Granules V. ${ }^{1)}$ Release Properties of Ethylcellulose Layered Matrix Granules
}

\author{
Atsuko FukuI, ${ }^{*, a}$ Ryuta FujII, ${ }^{a}$ Yorinobu Yonezawa, ${ }^{b}$ and Hisakazu SunadA ${ }^{b}$ \\ ${ }^{a}$ Ryukakusan Co., Ltd.; Higashi-Kanda, Chiyoda-ku, Tokyo 101-0031, Japan: and ${ }^{b}$ Faculty of Pharmacy, Meijo \\ University; Yagotoyama, Tempaku-ku, Nagoya 468-8503, Japan. \\ Received December 7, 2007; accepted January 28, 2008; published online January 30, 2008
}

In the pharmaceutical preparation of a controlled release drug, it is very important and necessary to understand the release properties. In previous papers, a combination of the square-root time law and cube-root law equations was confirmed to be a useful equation for qualitative treatment. It was also confirmed that the combination equation could analyze the release properties of layered granules as well as matrix granules. The drug release property from layered granules is different from that of matrix granules. A time lag occurs before release, and the entire release property of layered granules was analyzed using the combination of the square-root time law and cube-root law equations. It is considered that the analysis method is very useful and efficient for both matrix and layered granules. Comparing the granulation methods, it is easier to control the manufacturing process by tumbling granulation (method B) than by tumbling-fluidized bed granulation (method C). Ethylcellulose (EC) layered granulation by a fluidized bed granulator might be convenient for the preparation of controlled release dosage forms as compared with a tumbling granulator, because the layered granules prepared by the fluidized bed granulator can granulate and dry at the same time. The time required for drying by the fluidized bed granulator is shorter than that by the tumbling granulator, so the fluidized bed granulator is convenient for preparation of granules in handling and shorter processing time than the tumbling granulator. It was also suggested that the EC layered granules prepared by the fluidized bed granulator were suitable for a controlled release system as well as the EC matrix granules. granule

Key words ethylcellulose matrix; phenylpropanolamine hydrochloride; square-root time law; cube-root law; simulation; layered

Controlled drug release is a topic of much interest and it is important to understand the drug release process and properties. ${ }^{1-5)}$ It was confirmed in previous papers that ethylcellulose (EC) matrix granules and EC layered granules showed similar release properties. ${ }^{1)}$ There are many methods for the preparation of layered granules. EC layered granules were prepared using a high shear granulator i.e., High Speed Mixer, which is tumbling granulation (method B). Tumblingfluidized bed granulation (method C) used a fluidized bed with a rotating disk at the bottom and spray nozzles on the side. Hence, the layered granules used had an EC coating percent of 6 to $10 \%$ prepared by methods B and C. The release properties were mathematically assessed by Higuchi, ${ }^{6}$ but, it was considered that mathematical analysis of the release process was insufficient. Because the equation can not explain the entire release process. ${ }^{1-4)}$ In previous papers, the release process could be divided into two stages to understand the entire release process and these were analyzed using a combination of the square-root time law and cuberoot law equations. ${ }^{1-4)}$ Then, it was concluded that predicting drug release properties using this analysis method was useful.

In this paper, the release properties of two different products produced by tumbling granulation and tumbling-fluidized bed granulation were examined by a combination of the square-root time law and cube-root law equations.

\section{Experimental}

Materials The materials described in the previous paper were used. ${ }^{1-4)}$ Phenylpropanolamine hydrochloride (PPA) (Powder, Alps Pharmaceutical Ind. Co., Ltd., Gifu), ethylcellulose $10 \mathrm{cps}$ (EC) (ETHOCEL STD $10 \mathrm{cps}$, DOW Chemical, Tokyo), Nonpalel 103 (NP) (Sugar cubes, Freund Industrial
Co., Ltd., Tokyo), Talc, Polyethylenglycol 6000 (PEG), $\mathrm{Fe}_{2} \mathrm{O}_{3}$ and $90 \%$ ethanol (EtOH) (Wako Pure Chemical Industries, Ltd., Osaka) were used.

Equipment The equipment described in the previous paper was used. $^{1-4)}$ Preparation by a high shear granulator (High Speed Mixer, LFSGS-5, volume 5.01, Fukae Ind. Co., Ltd., Hyogo) was abbreviated as method $\mathrm{B}$, and preparation by a fluidized bed with rotor disk granulator (SPIR-AFLOW, SFC-MINI, Freund Industrial Co., Ltd., Tokyo) was abbreviated as method $\mathrm{C}$, and were used for granulation.

Preparation of Two Kinds of Granules The formulations for the preparation of the EC layered granules by method B (Granule B) and method C (Granule C) are shown in Table 1.

The PPA layered-coating Granules B and C were prepared as follows. Appropriate amounts of NP were layered by PPA with binder solution using a high shear granulator and a fluidized bed with a rotor disk granulator under an agitator speed of $200 \mathrm{rpm}$. They were rotated for $5 \mathrm{~min}$ for drying. The EC layered granules were then prepared using a coating solution of EC. They were dried overnight at $40-50{ }^{\circ} \mathrm{C}$ in a box-type drying machine and for $30 \mathrm{~min}$ at $40-50^{\circ} \mathrm{C}$ in a fluidized bed, respectively. After drying, sieved granules of 12 mesh pass $/ 18$ mesh on were used.

Thus, EC layered granules, i.e., Granules B and $\mathrm{C}$, were obtained. The preparation process is shown in Fig. 1. EC coating percent (6-10\%) was estimated from the increase after coating granules. The prepared granules were abbreviated as Gr-B6- Gr-B10 and Gr-C6- Gr-C10

Release Studies Dissolution apparatus (type NTR-VS6P, Toyama Sangyo Co., Ltd., Osaka) coupled to a flow cell set (type CPS-240B \& CPS Controller, Toyama Sangyo Co., Ltd., Osaka) in a double-beam spectrophotometer (type UV-160A, Shimadzu Co., Ltd., Tokyo) attached to an auto sampler (type Auto Sampler-W, Toyama Sangyo Co., Ltd., Osaka) was used. Granules B or C were put into the dissolution apparatus, and the release measurement was carried out with $500 \mathrm{ml}$ of buffer solution (Japan Pharmacopoeia (14th) first solution $\mathrm{pH} 1.2$ ) at a paddle rotation speed of $100 \mathrm{rpm}$ at $37^{\circ} \mathrm{C}$. The released amount was evaluated from absorbance measurements at $257 \mathrm{~nm}$.

\section{Results and Discussion}

Release Profile The dissolution test was examined. The 
Table 1. Formulation of Layered Granules

\begin{tabular}{|c|c|c|c|c|c|}
\hline $\begin{array}{l}\text { Granule B } \\
\text { Granule C }\end{array}$ & $\begin{array}{l}\text { Gr-B6 } \\
\text { Gr-C6 }\end{array}$ & $\begin{array}{l}\text { Gr-B7 } \\
\text { Gr-C7 }\end{array}$ & $\begin{array}{l}\text { Gr-B8 } \\
\text { Gr-C8 }\end{array}$ & $\begin{array}{l}\text { Gr-B9 } \\
\text { Gr-C9 }\end{array}$ & $\begin{array}{l}\text { Gr-B10 } \\
\text { Gr-C10 }\end{array}$ \\
\hline \multicolumn{6}{|l|}{ Composition (amount: g) } \\
\hline PPA & & & 500 & & \\
\hline NP103 & & & 750 & & \\
\hline \multicolumn{6}{|l|}{ Binder solution } \\
\hline EC concentration $(\%)$ & & & 7 & & \\
\hline $\mathrm{EC \# 10}(\mathrm{g})$ & & & 35 & & \\
\hline Volume (ml) & & & 500 & & \\
\hline \multicolumn{6}{|l|}{ Coating solution } \\
\hline EC concentration $(\%)$ & & & 7.00 & & \\
\hline Talc concentration $(\%)$ & & & 1.00 & & \\
\hline PEG concentration $(\%)$ & & & 1.00 & & \\
\hline EtOH concentration $(\%)$ & & & 90.00 & & \\
\hline $\mathrm{Fe}_{2} \mathrm{O}_{3}$ concentration $(\%)$ & & & 0.01 & & \\
\hline Coating EC\#10 (g) & 83.55 & 98.85 & 114.60 & 130.80 & 147.48 \\
\hline Volume (ml) & 1193.50 & 1412.20 & 1637.15 & 1868.61 & 2106.90 \\
\hline \multicolumn{6}{|l|}{ for Dissolution test } \\
\hline Granule (mg) & 116.97 & 169.47 & 171.90 & 174.40 & 176.98 \\
\hline PPA (mg) & 60 & 60 & 60 & 60 & 60 \\
\hline Coating EC\#10 (\%) & 6.0 & 7.0 & 8.0 & 9.0 & 10.0 \\
\hline
\end{tabular}

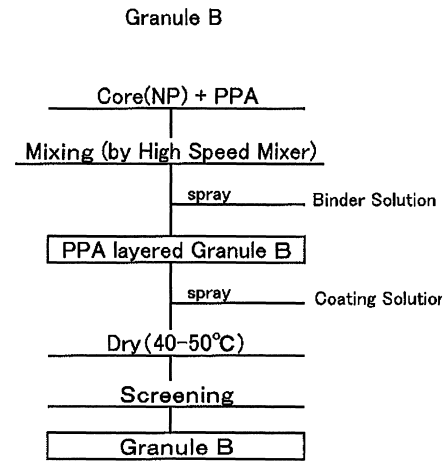

Granule C

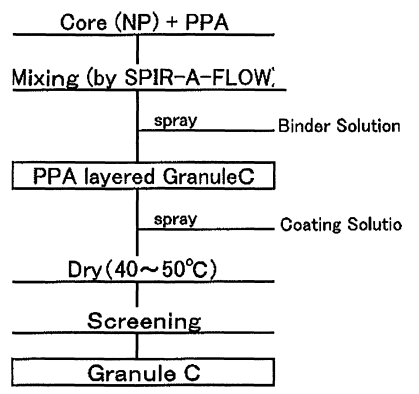

Fig. 1. Flow Chart of Granule Preparation

release profiles are shown using the release ratio $\left(m_{\mathrm{r}}\right)$ in Fig. 2.

The release ratio $\left(m_{\mathrm{r}}\right)$ is expressed as:

$$
m_{\mathrm{r}}=m / M_{0}
$$

where $M_{0}$ is the initial PPA amount and $m$ is the released PPA amount at time $t$.

The release process should be treated quantitatively to obtain clear release properties, as described in previous papers. ${ }^{1-4)}$ Following the previously reported methods, ${ }^{1-4)}$ the release process could be divided into two stages. In the initial stage, PPA was released from the gel layer of swollen EC. In the second stage, the drug existing below the gel layer dissolved, and was released through the gel layer. The entire release process was treated by a combination of the square-root time law and cube-root law equations. Hence, the effects of factors on release properties were evaluated quantitatively.

Analysis of Entire Release Process The release processes of Granules B and C were analyzed together using a semilogarithmic equation. ${ }^{7,8)}$ The applicability of the equation to the second stage release process was also examined previously, ${ }^{1-4)}$ however, it was found that the semilogarithmic equation was not applicable to treatment in these release
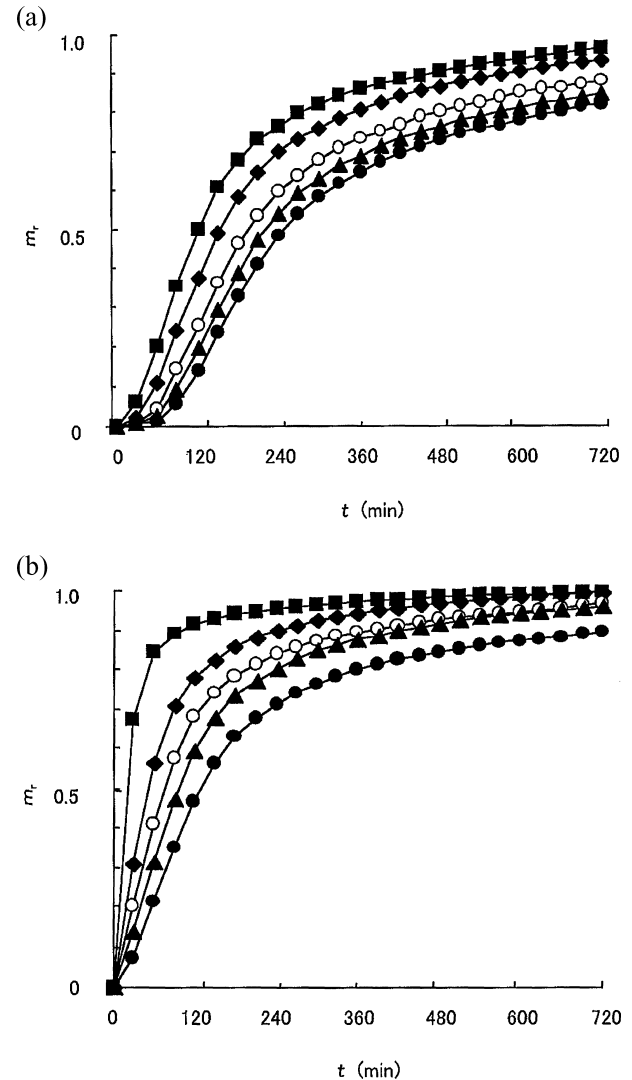

Fig. 2. (a) Release of PPA from Granule $B$

$\boldsymbol{\square}, \mathrm{Gr}-\mathrm{B} 6 ; \bullet$, Gr-B7; O, Gr-B8; $\boldsymbol{\Delta}$, Gr-B9;, Gr-B10

(b) Release of PPA from Granule $\mathrm{C}$

$\boldsymbol{\square}, \mathrm{Gr}-\mathrm{C} 6 ; \diamond, \mathrm{Gr}-\mathrm{C} 7$; O, Gr-C8; $\boldsymbol{\Delta}$, Gr-C9; ๑, Gr-C10.

studies because of a lack of correlation with the measured values. Therefore, the release process could be divided into two stages and the initial and second stages were analyzed by the square-root time law equation and cube-root law equa- 
tion, respectively.

The square-root time law equation ${ }^{6,9)}$ was expressed as the following equation in terms of the drug-release ratio.

$$
m_{\mathrm{r}}=K_{\mathrm{H}} \sqrt{t}
$$

where $K_{\mathrm{H}}$ is the apparent release rate constant and $t$ is the release time, but the entire release process could not be analyzed. Therefore, the second release process was treated using the cube-root law equation in the same manner as described previously. ${ }^{1-4)}$

The cube-root law equation for a single component is expressed as ${ }^{10,11)}$ :

$$
\left(M / M_{0}\right)^{1 / 3}=1-(1 / 3) k S_{\mathrm{SP}} C_{\mathrm{S}} t=1-K_{\mathrm{C}} t
$$

where, $M\left(=M_{0}-m\right)$ is the undissolved amount remaining in the solution, $k$ is the intrinsic release rate constant, $S_{\mathrm{SP}}$ is the specific surface area, $C_{\mathrm{S}}$ is the solubility and $K_{\mathrm{C}}$ is the summarized release rate constant, respectively. As $M / M_{0}$ can be rewritten as $1-m_{\mathrm{r}}$, the cube-root law equation for a system of more than two components is expressed as:

$$
\left(1-m_{\mathrm{r}}\right)^{1 / 3}=1-K_{\text {app }} t
$$

where $K_{\text {app }}$ is the apparent release rate constant.

Following Eqs. 2 and 4, the results obtained for Gr-B10 and Gr-C10 are shown in Fig. 3 as an example.

In Fig. $3 \mathrm{a}$, the apparent release rate constant, $K_{\mathrm{H}}$, was evaluated as the initial slope of the straight line. The estimated $K_{\mathrm{H}}$ value of $\mathrm{Gr}-\mathrm{C} 10$ was $0.0726 \mathrm{~min}^{-1 / 2}$. The initial stage was a water channel-forming process, and PPA was released from the gel layer of swollen EC.

In Fig. $3 b$ of the second stage, the estimated $K_{\text {app }}$ value of Gr-C10 was $0.0007 \mathrm{~min}^{-1}$. The obtained straight line of GrC10 was expressed as follows.

$$
\left(1-m_{\mathrm{r}}\right)^{1 / 3}=0.83-0.0007 t
$$

Hence, the release ratio in the second stage could be simulated using the equation:

$$
m_{\mathrm{r}, \mathrm{c}}=1-(0.83-0.0007 t)^{3}
$$

where $m_{\mathrm{r}, \mathrm{c}}$ is the release ratio simulated by the cube-root law equation. The simulated values are shown in the figure, and a fairly good relationship was obtained; therefore, the second release stage could be well expressed by the generalized equation $^{3)}$ :

$$
\left(1-m_{\mathrm{r}}\right)^{1 / 3}=a-K_{\mathrm{app}} t
$$

where $a$ is the intersection at the $y$-axis in the cube-root law plot. The release process might also be simulated as:

$$
m_{\mathrm{r}, \mathrm{c}}=1-\left(a-K_{\mathrm{app}} t\right)^{3}
$$

Release and simulation curves obtained by using $K_{\mathrm{H}}, K_{\text {app}}$, Eq. 2, and Eq. 8 are shown in Fig. 4.

Simulation curves fit well with the measured release curves, ${ }^{12}$ thus, the validity of the analysis method for Granules $\mathrm{B}$ and $\mathrm{C}$ was confirmed as expected from the previous paper. ${ }^{1-4)}$ It was therefore confirmed that the release process could be divided into two stages, and the entire release process treated by a combination of the square-root time law and cube-root law equations, irrespective of the dose preparation, i.e., Granules $\mathrm{B}$ and $\mathrm{C}$.

Changes in $\boldsymbol{K}_{\mathbf{H}}$ with EC Coating Ratio $K_{\mathrm{H}}$ is an appar-
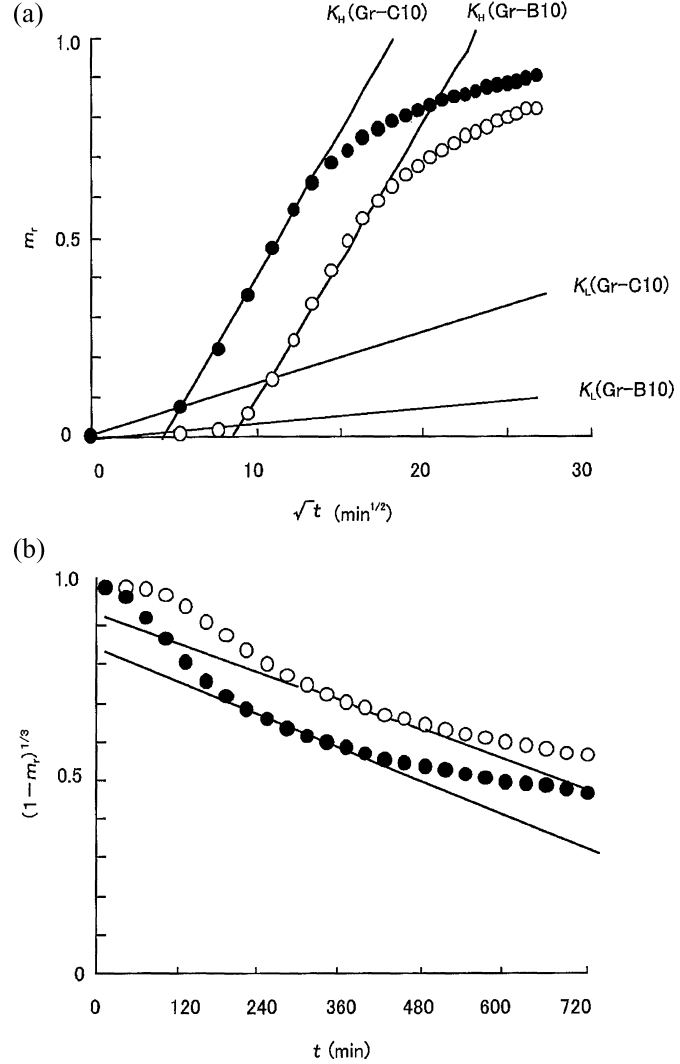

Fig. 3. (a) Analysis of Release Properties by the Square-Root Time Law Equation

$\mathrm{O}, \mathrm{Gr}-\mathrm{B} 10 ;-\mathrm{Gr}-\mathrm{C} 10 ; K_{\mathrm{H}}, K_{\mathrm{L}}$, simulation using the square-root time law equation.

(b) Analysis of Release Properties by the Cube-Root Law Equation

O, Gr-B10; $\bullet$ Gr-C10; - , simulation using the cube-root law equation.

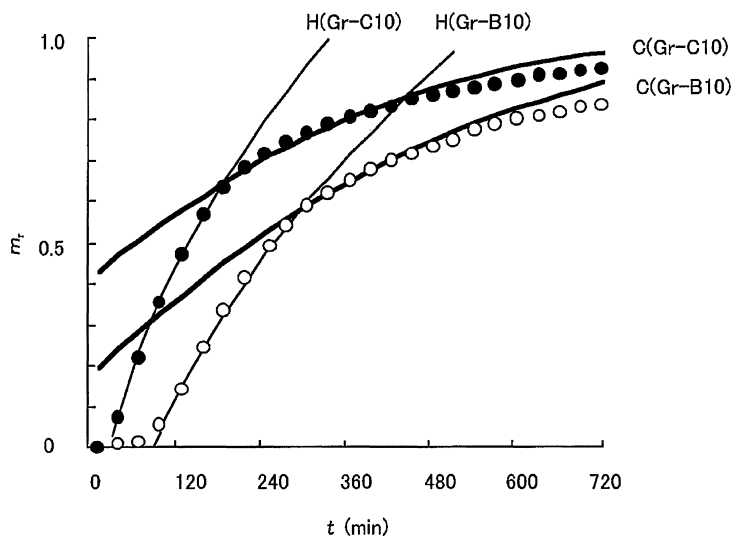

Fig. 4. Release and Simulation Curves

$\mathrm{O}, \mathrm{Gr}-\mathrm{B} 10$;, Gr-C10; curve $\mathrm{H}$, simulation using the square-root time law equation; curve $\mathrm{C}$, simulation using the cube-root law equation.

ent release rate constant in the initial stage obtained by applying the square-root time law equation. The relationship between the $K_{\mathrm{H}}$ and EC coating percent is shown in Fig. 5.

The $K_{\mathrm{H}}$ value decreased by increasing the EC coating percent. This might have been caused by swelling and the gel formation property of EC. EC is water insoluble, and the thickness and formation time of the gel layer depend on the EC coating percent. So release of PPA from Granules B and $\mathrm{C}$ delayed by increasing the EC coating percent. 


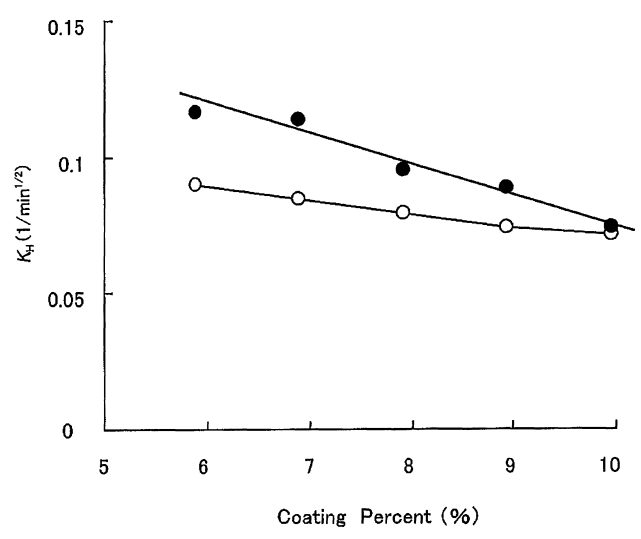

Fig. 5. Relationship between $K_{\mathrm{H}}$ and EC Coating Percent

O, Granule B; $\bullet$, Granule C.

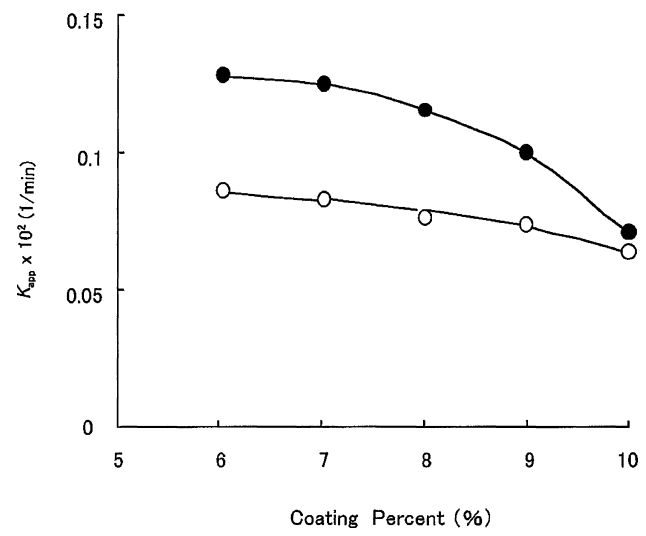

Fig. 6. Relationship between $K_{\text {app }}$ and EC Coating Percent

O, Granule B; $\bullet$, Granule C.

Changes in $K_{\text {app }}$ with EC Coating Ratio $K_{\text {app }}$ is the apparent dissolution rate in the second release stage obtained by applying the cube-root law equation. The relationship between the $K_{\text {app }}$ and EC coating percent is shown in Fig. 6.

The $K_{\text {app }}$ value decreased by increasing the EC coating rate, because PPA must pass through the swelling EC layer. When the EC coating percent is $10 \%$, i.e. Gr-B10 and GrC10 showed similar $K_{\text {app }}$ values. It was considered that the surface coverage and thickness of EC layer was almost complete as the EC coating percent was $10 \%$.

Connect Point of the First and Second Release Processes The connection point of the square-root time law and cube-root law equations should play an important role in evaluating the entire release process in addition to $K_{\mathrm{H}}$ and $K_{\text {app. }}$. The release time and release ratio at the connection point of these simulation curves were expressed by $t_{\mathrm{c}}$ and $m_{\mathrm{c}}$, respectively. Changes of $t_{\mathrm{c}}$ and $m_{\mathrm{c}}$ with the EC coating percent were examined as shown in Fig. 7.

$\sqrt{t_{\mathrm{c}}}$ was the length of time of the initial release stage, and $\sqrt{t_{\mathrm{c}}}$ of Granule $\mathrm{C}$ was shorter than Granule B. i.e., the water channel-forming process in the Granule $\mathrm{C}$ took longer than Granule B. The $m_{\mathrm{c}}$ values of Granule B and C were shown constant (around 0.6 and 0.7 ) as the EC coating percent was over $8 \%$ and over $7 \%$, respectively. In other words, as the $m_{\mathrm{c}}$ values were nearly constant, it was necessary for the EC coating percent of Granule $\mathrm{B}$ and $\mathrm{C}$ to be over $8 \%$ and over $7 \%$, respectively. As the EC coating ratio increased, surface (a)

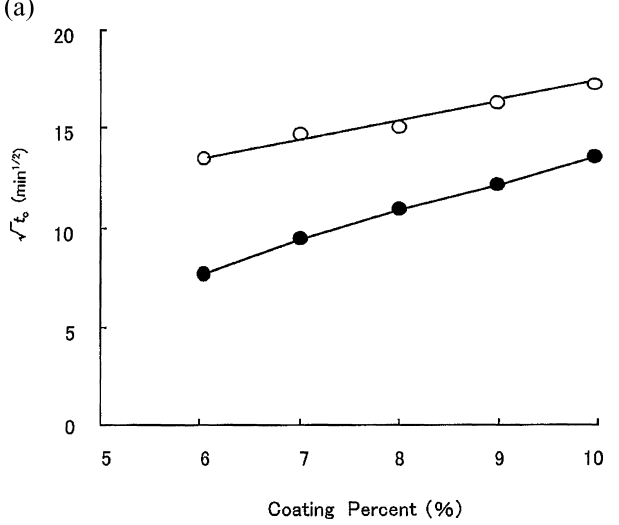

(b)

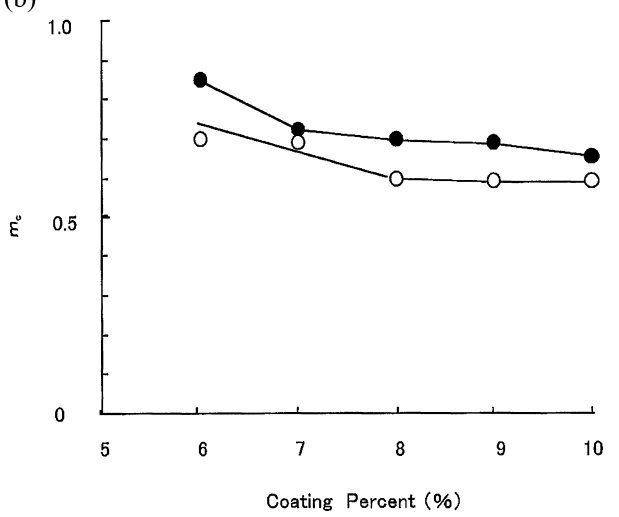

Fig. 7. (a) Changes of $\sqrt{t_{\mathrm{c}}}$ with EC Coating Percent

$\mathrm{O}$, Granule B; $\bullet$, Granule C.

(b) Changes of $m_{\mathrm{c}}$ with EC Coating Percent

$\bigcirc$, Granule B; $\bullet$, Granule C.

coverage and thickness of the EC layer increased. When the EC coating percent of Granule $\mathrm{B}$ and $\mathrm{C}$ increased over $8 \%$ and over $7 \%$, the layered surface coverage was nearly perfect and then their thickness increased.

Changes in $\boldsymbol{K}_{\mathrm{L}}$ and $\boldsymbol{T}_{\mathrm{L}}$ with EC Coating Ratio EC layered granules showed a lag time $\left(T_{\mathrm{L}}\right)$ in the release process, which could not be observed for EC matrix granules. In the release pass-forming process, $K_{\mathrm{L}}$ is an apparent release rate constant before the initial release stage. It is obtained by applying the straight line which passes along time points 0 and 30 min temporarily by the square-root time law equation. $T_{\mathrm{L}}$ is the connect point of these stages. The relationship between $K_{\mathrm{L}}$ and $T_{\mathrm{L}}$ with EC coating ratio is shown in Fig. 8.

At the early coating ratio, granules had few layers, and their surface coverage was incomplete. Thus, PPA was released quickly from PPA layered Granules B and C. Therefore, the value of $T_{\mathrm{L}}$ was shown to be small and $K_{\mathrm{L}}$ was shown to be large at that time, which was a transition stage.

It was considered that $T_{\mathrm{L}}$ and $K_{\mathrm{L}}$ are influenced by the character of the coating layer. The $T_{\mathrm{L}}$ value increased and the $K_{\mathrm{L}}$ value decreased with increasing EC coating percent. At the same time, the value of $K_{\mathrm{H}}$ and $K_{\mathrm{C}}$ decreased. It was considered that they depended on increasing the surface coverage and thickness of the EC layer.

Granulation Method and Release Properties With the increasing EC coating ratio, the $m_{\mathrm{c}}$ values of Granules B and $\mathrm{C}$ were nearly constant. But the value of $m_{\mathrm{c}}$ obtained from Granule $\mathrm{C}$ was larger than that obtained from Granule B at 


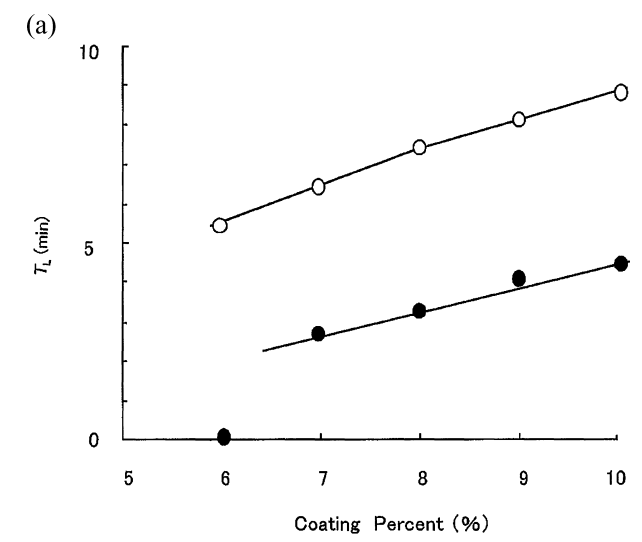

(b)

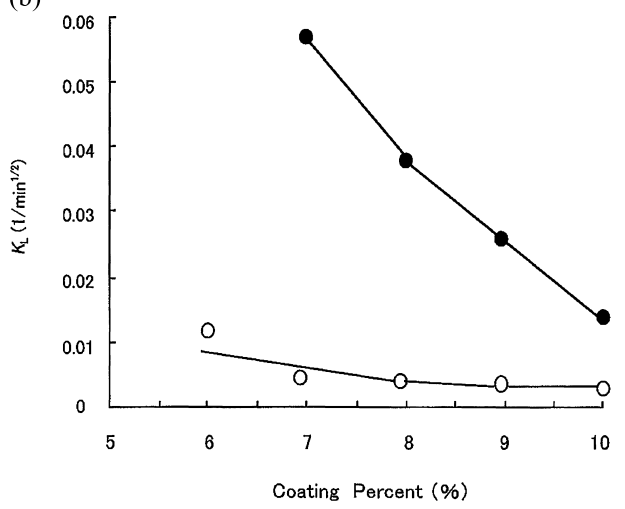

Fig. 8. (a) Changes of $T_{\mathrm{L}}$ with EC Coating Percent

$\mathrm{O}$, Granule B; $\bullet$, Granule C.

(b) Changes of $K_{\mathrm{L}}$ with EC Coating Percent

$\mathrm{O}$, Granule B; $\bullet$, Granule C.

each point of the EC coating percent. The initial stage was a water channel-forming process, and $m_{\mathrm{c}}$ was the PPA release ratio at the end of this stage. So Granule $C$ released PPA more than Granule $\mathrm{B}$ in the initial stage. Comparing the value of $\sqrt{t_{\mathrm{c}}}$, at the end of the water channel-forming process, Granule B was larger than Granule C. Thus, Granule B could not release PPA easier than Granule $C$ in the initial stage; therefore, it was considered that Granule $\mathrm{B}$ has an accumulated thick coating layer. The value of $K_{\mathrm{L}}, K_{\mathrm{H}}, K_{\mathrm{C}}$, of Granule $\mathrm{B}$ changed in a narrow region depending on the EC coating ratio. In the manufacturing process, control of the coating process depends on the weight control of the coating solution, i.e. the EC coating ratio. Thus, with Granule $\mathrm{B}$, it is difficult to control the coating process of the EC coating ratio, because the release property of Granule B was significantly affected by a low EC coating ratio. It was therefore considered that Granule B was infusion for the manufacturing process and it was difficult to control the pharmaceutical quality. Thus, control of the release property of Granule $\mathrm{C}$ was easier than Granule B.

\section{Conclusion}

When release and/or dissolution tests are carried out, the release process should be treated quantitatively. A combination of the square-root time law and cube-root law equations was confirmed to be a useful equation for qualitative treatment. It was also considered that this method was applicable for practical simulations and prediction of the release process within the measured conditions.

The drug release property of layered granules is different from matrix granules. EC layered granules showed a lag time $\left(T_{\mathrm{L}}\right)$ in the release process, which could not be observed for EC matrix granules. The lag time increased by increasing the coating ratio, and it was considered that the lag time is an indicator of surface coverage.

The entire release process of layered granules was analyzed using a combination of the square-root time law and cube-root law equations. It is considered that is analysis method is very useful and efficient for both matrix and layered granules.

Comparing the granulation methods, it is easier to control the manufacturing process of tumbling granulation (method B) than tumbling-fluidized bed granulation (method C).

\section{References}

1) Fukui A., Fujii R., Yonezawa Y., Sunada H., Chem. Pharm. Bull., 55, 1569-1573 (2007).

2) Fukui A., Fujii R., Yonezawa Y., Sunada H., Chem. Pharm. Bull., 54, 1091-1096 (2006).

3) Fukui A., Fujii R., Yonezawa Y., Sunada H., Chem. Pharm. Bull., 52, 298-302 (2004)

4) Fukui A., Fujii R., Yonezawa Y., Sunada H., Chem. Pharm. Bull., 50, 1439-1444 (2002).

5) Yonezawa Y., Ishida S., Sunada H., Chem. Pharm. Bull., 49, 1448 1451 (2001).

6) Higuchi T., J. Soc. Cosmetic Chemists, 11, 85-97 (1960).

7) Guojie X., Sunada H., Chem. Pharm. Bull., 43, 483-487 (1995).

8) Guojie X., Ruhuna Z., Wei C., Sunada H., J. Chin. Pharm. Sci., 9, 26-30 (2000).

9) Higuchi T., J. Pharm. Sci., 52, 1145-1149 (1963).

10) Sunada H., Shinohara I., Otsuka A., Yonezawa Y., Chem. Pharm. Bull., 37, 1889-1894 (1989).

11) Hixson A. W., Crowell J. H., Ind. Eng. Chem., 23, 923 -931 (1931).

12) Higuchi T., J. Pharm. Sci., 50, 874-875 (1961). 